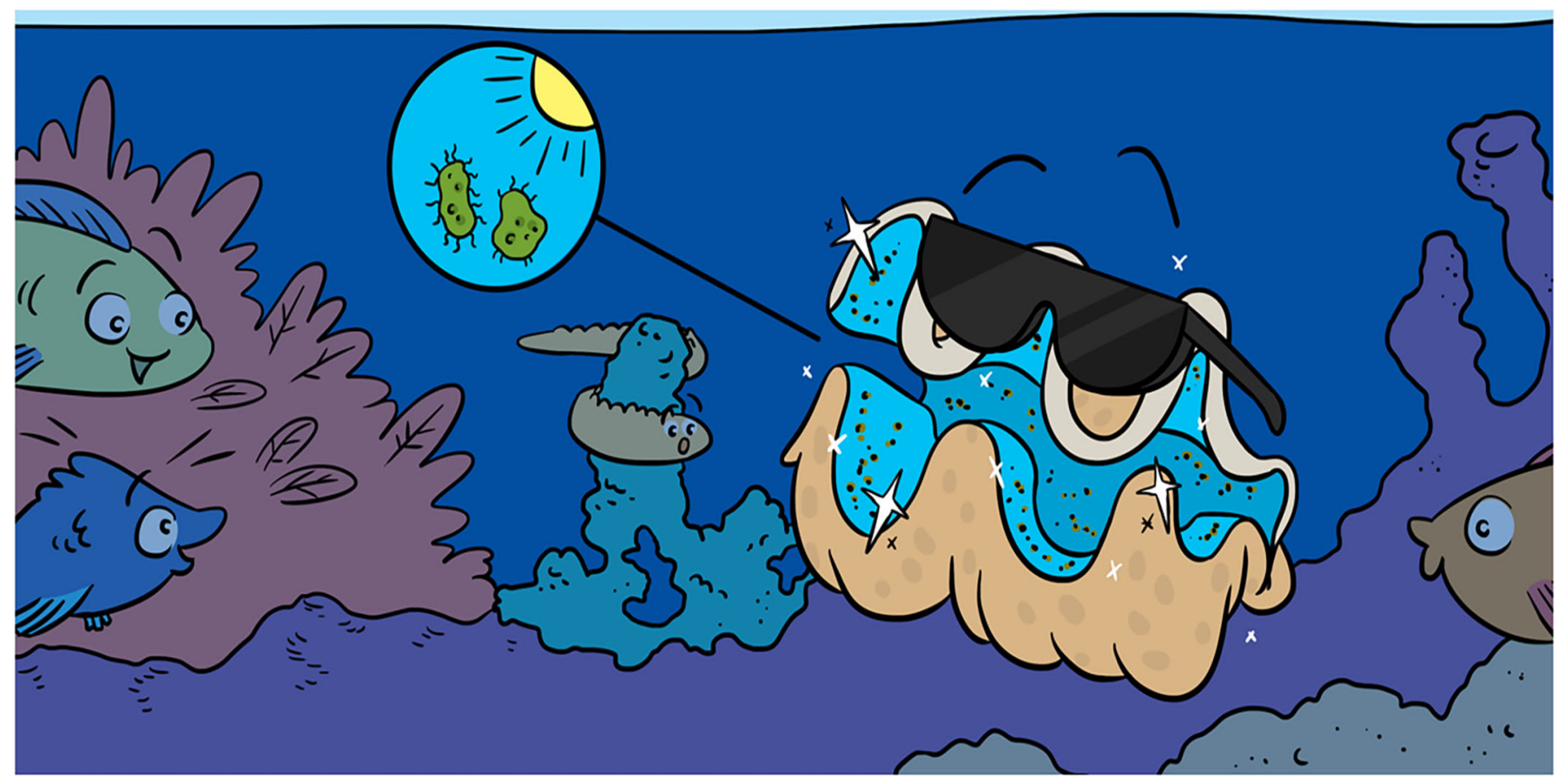

\title{
THE SPARKLING TAN: HOW GIANT CLAMS AVOID SUNBURNS
}

\section{Susann Rossbach ${ }^{1 *}$, Sebastian Overmans ${ }^{1}$, Ram C. Subedi ${ }^{2}$ and Carlos M. Duarte ${ }^{1}$}

${ }^{1}$ Red Sea Research Centre (RSRC) and Computational Bioscience Research Center (CBRC), Biological and Environmental Science and Engineering Division (BESE), King Abdullah University of Science and Technology (KAUST), Thuwal, Saudi Arabia

${ }^{2}$ Photonics Laboratory, Computer, Electrical and Mathematical Sciences and Engineering Division (CEMSE), King Abdullah University of Science and Technology (KAUST), Thuwal, Saudi Arabia

YOUNG REVIEWER:

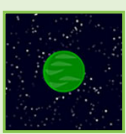

FABIÁN

AGE: 14
As their name suggests, giant clams are among the biggest clams on earth, and they are very colorful animals that live in coral reefs. Giant clams get help from tiny organisms inside their mantles, the colorful part between their shells. These little helpers, tiny microalgae, can use sunlight and carbon dioxide to produce food, which they share with the clams. That is why these clams can grow so big! In return, the clams provide the microalgae with some nutrients. Although sunlight is very important for food production in these organisms, excessive sunlight can lead to a sunburn, like in humans. Therefore, the clams had to evolve their special sparkling tan, a natural sun protection that is a very effective way to protect themselves, and the microalgae inside their mantles, from too much sunlight and from getting a sunburn. 
Figure 1

(A) The outer shell of a clam protects the soft, inner parts of its body. (B) The colorful mantles of giant clams contain symbiotic microalgae, which perform photosynthesis, and cells called iridocytes, which have mirror-like crystal plates that can reflect UV light from the sun and protect the clams from sun damage.

\section{MICROALGAE}

Tiny, single-celled organisms that can fix carbon from the atmosphere like plants do on land.

\section{MANTLE}

The outer, fleshy part of a clam's body. In giant clams, the mantle is very colorful, with shades of blue, green, and brown.

\section{MUTUALISTIC SYMBIOSIS}

A relationship between two or more species, in which both organisms benefit from the interaction in some way.
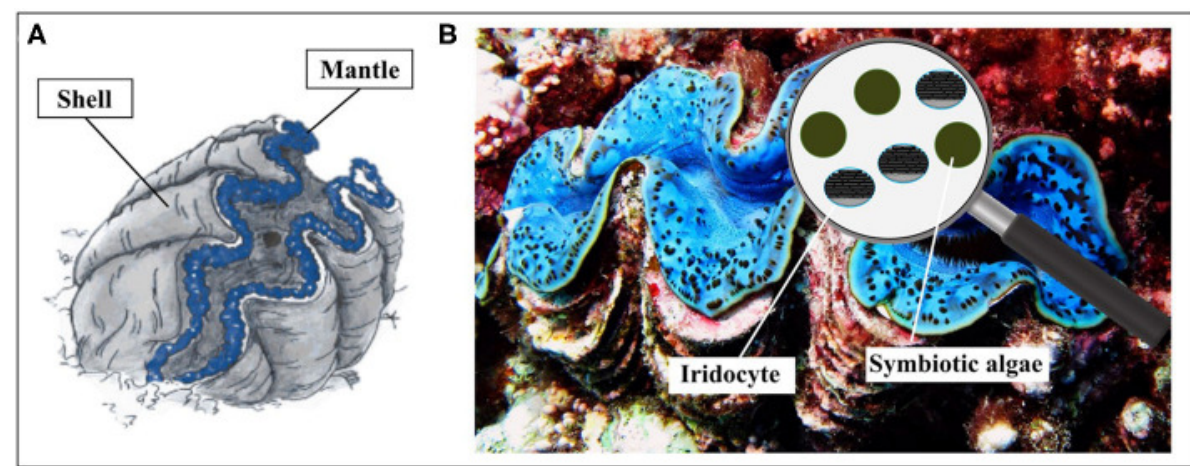

Figure 1

\section{GIANT CLAMS AND THEIR TINY FRIENDS}

When people hear the word "reef," they immediately think of corals. However, there are other big, colorful, and important animals living in these reefs, such as the giant clams, which are common in coral reefs of the tropical Indian and Pacific Oceans. These clams are not only beautiful to look at, but they are also important members of a reef. For example, many fishes eat them, some animals and plants can grow on the outsides of their shells, and there are even animals (like tiny shrimps) that live inside their bodies [1].

As the name indicates, giant clams can become very big. Some of them can even grow over one meter long-probably bigger than the sink in your bathroom at home! Scientists believe that one of the reasons giant clams can become so big is that they get help from other organisms. Those helpers are tiny single-celled microalgae that live in the outer, fleshy part of the clam's body, called the mantle (Figure 1A). These microalgae, like plants, can carry out photosynthesis, which uses the energy of sunlight and carbon dioxide to produce food. The microalgae that live inside the giant clams produce so much food via photosynthesis that they can feed themselves and share some of that food with the giant clam. In return, the clam protects the microalgae against predators while also giving the microalgae some necessary nutrients, such as nitrogen. This relationship is called a mutualistic symbiosis, and you might have heard of it before because the same relationship exists between corals and their microalgae. Giant clams rely heavily on the food provided by their symbiotic microalgae. Scientists assume that this symbiosis, and the extra energy that it provides for the clams, is one of the main reasons why giant clams can reach their large sizes [2].

\section{GIANT CLAMS CAN GET SUNBURNS}

Just like plants, the giant clam's symbiotic microalgae need enough light to produce food via photosynthesis. Therefore, giant clams must live in shallow water, where they are close to the surface and thus to 


\section{ULTRAVIOLET}

\section{LIGHT}

Highly energetic light that cannot be seen by the human eye. UV light from the sun can burn or damage skin tissue.

\section{IRIDOCYTE}

Tiny cells inside the mantle of giant clams, which contain mirror-like plates that can reflect ultraviolet light. the sunlight that enters the ocean. But, as happens to humans, staying in the sun without the protection of shade or sunscreen can become dangerous after a while. That is because sunlight consists of different colors of light. You have probably seen a rainbow with its beautiful colors, ranging from violet to blue and green, to yellow, orange, and red. The color of the light is connected to its energy level, with blue light being more energetic than red light. The light with the highest energy is called ultraviolet UV light. UV light is not visible with our eyes and it has more energy than the colors of light you can see in the rainbow. In fact, UV light has so much energy that it can damage or even kill cells of animals and plants [3]. You have probably experienced that yourself! Maybe you spent a day out in the sun but forgot to put on sunscreen. Perhaps your skin got red and itchy, or even started peeling after a few days. The same can happen to all other organisms if they stay in the bright sun for too long without any protection. Because giant clams always sit in the same spot and cannot move to the shade, the same would also happen to them. But, luckily, these animals evolved a very clever way to protect themselves.

\section{THE SPARKLING TAN-A SUNSCREEN FOR GIANT CLAMS}

Close to the microalgae in their mantles, giant clams have tiny cells called iridocytes (Figure 1B). The word "iridocyte" comes from Latin and ancient Greek, where "irido" means "rainbow" and "cyte" means "cell." The name "rainbow cell" makes sense, because researchers think iridocytes are one of the reasons giant clams are so colorful, with mantles in beautiful shades of blue, green, and brown.

Inside iridocytes, there are small plates stacked on top of each other. These plates are made from a crystal, which makes them look and act like tiny mirrors. When harmful UV light hits these cells, some of it is immediately reflected by the tiny mirror-like plates [4] (Figure 2). Thanks to these tiny mirrors, the reflected UV light cannot reach or damage the cells of the clams or the microalgae, because it bounces away before it can reach them. That is a great natural sunscreen! However, some of the UV light travels into the iridocytes, where it bounces back and forth between the tiny mirror-like plates. By doing so, it loses some of its energy, which makes the light less dangerous to the clams and their microalgae. By the time the light leaves the iridocytes, it has less energy and has changed its color from ultraviolet to blue [5].

The blue light that comes out of the iridocytes is the reason why many giant clams have such a bright blue color, like the clam shown in Figure 1. Other organisms, such as chameleons or copepods (miniscule relatives of crabs and lobsters), also have iridocytes that are responsible for their bright colors. These animals often use their coloration for camouflage or to attract mates. But, as you can imagine, giant clams 
Figure 2

Iridocyte cells have mirror-like plates that either reflect UV light or bounce it back and forth between plates. The bouncing UV light loses energy and eventually leaves the cell as less energetic blue light.

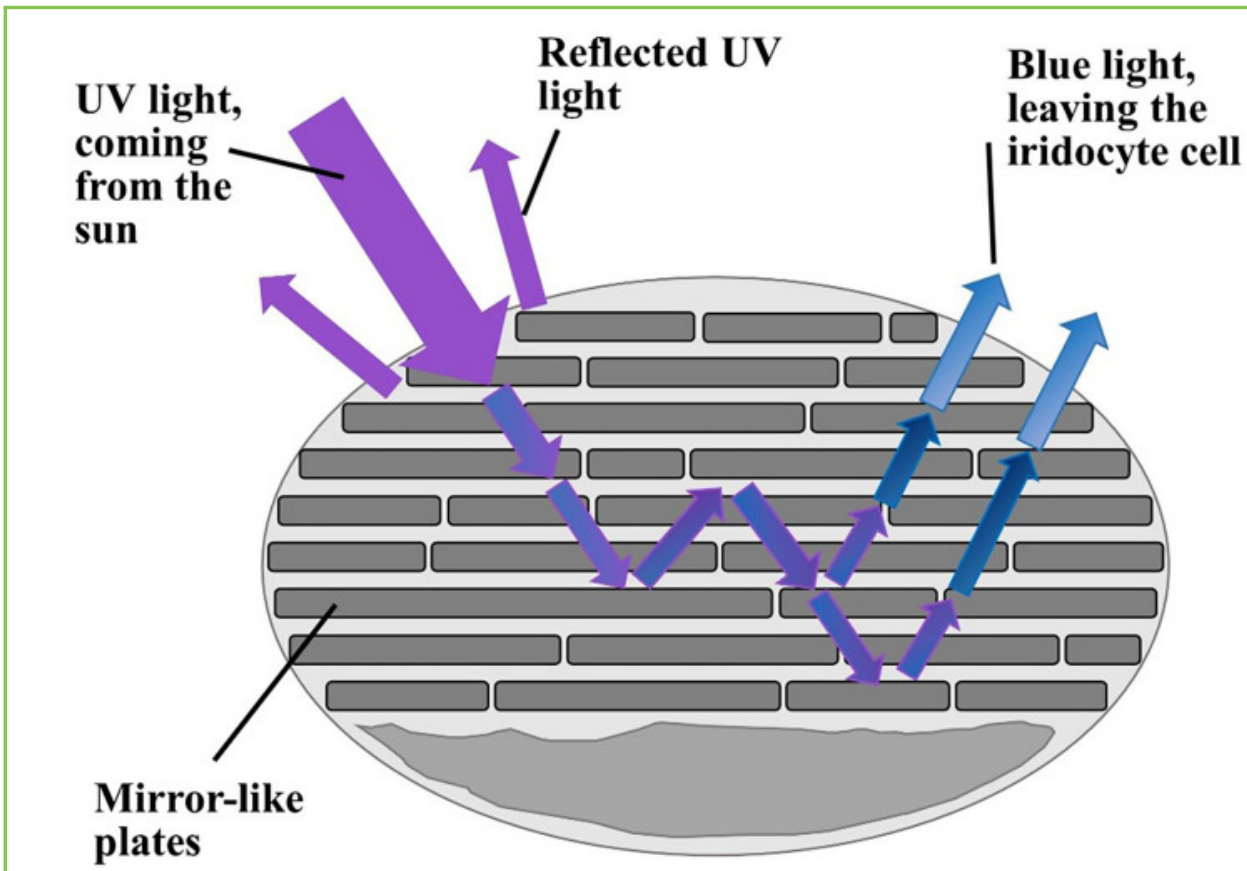

Figure 2

are not very good at hiding. In fact, with their bright colors, they do quite the opposite! Moreover, giant clams do not meet to mate, so they do not use their bright colors to look beautiful to attract potential partners. So, why do giant clams produce blue light? Not only does it help the clams avoid sunburn, it is also the perfect light for the microalgae to use for photosynthesis! This means the iridocytes not only provide a highly effective sunscreen, but they also help the symbiotic microalgae to grow, by giving them their favorite color of light!

\section{IRIDOCYTES AND MICROALGAE MAKE GIANT CLAMS SO \#CLAMOROUS}

While iridocytes have a blue color due to the blue light they emit, microalgae have a green color. Most organisms that perform photosynthesis use only a little of the green light that comes from the sun, so most of this light gets reflected. That is why plants and many macroalgae appear mostly green. Scientists believe that the beautiful colors found in giant clams result from different mixes of iridocytes (blue/turquoise) and microalgae (green/brownish). If a clam has more microalgae than iridocytes within its mantle, it has a more brownish coloration (Figure 3A), while clams with more iridocytes than microalgae look more blueish or even turquoise (Figure 3B).

This special relationship between giant clams and their microalgae, and the ways they developed to support and protect each other, make giant clams a fascinating animal for scientists to study. While is it 


\section{Figure 3}

The mix of iridocytes and microalgae determines the color of the giant clam's mantle. (A) A brown giant clam has more microalgae than iridocytes. (B) A turquoise/blue giant clam has more iridocytes than microalgae.
A

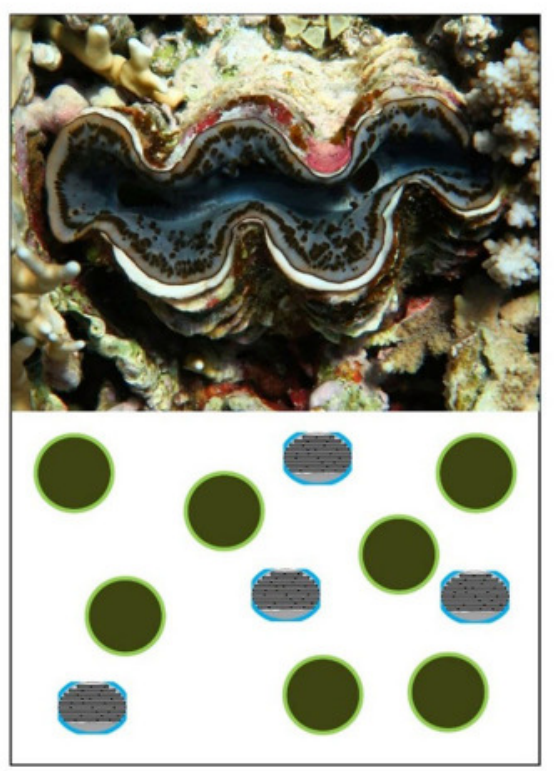

B

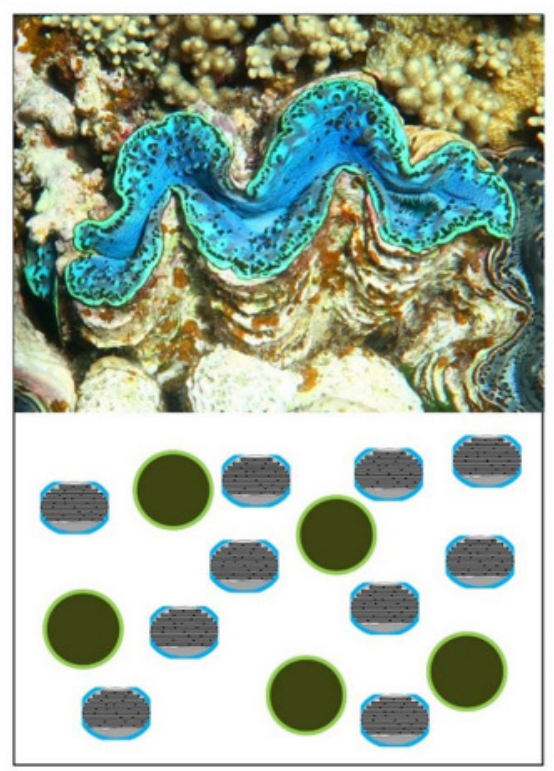

Figure 3

important to understand the life of these animals and how they survive in the oceans, it is also essential to learn more about their specialized cells, the iridocytes. One day, knowledge of how iridocytes function might inspire technologies that work with light and colors to bring us, for example, better computer or TV screens. Who would have guessed that these ancient clams could be the key to technologies of the future!

\section{ORIGINAL SOURCE ARTICLE}

Rossbach, S., Subedi, R. C., Ng, T. K., Ooi, B. S., and Duarte, C. M. 2020. Iridocytes mediate photonic cooperation between giant clams (Tridacninae) and their photosynthetic symbionts. Front. Mar. Sci. 7:465. doi: 10.3389/fmars.2020.00465

\section{REFERENCES}

1. Neo, M. L., Eckman, W., Vicentuan, K., Teo, S. L. M., and Todd, P. A. 2015. The ecological significance of giant clams in coral reef ecosystems. Biol. Conserv. 181:111-23. doi: 10.1016/j.biocon.2014.11.004

2. Rossbach, S., Saderne, V., Anton, A., and Duarte, C. M. 2019. Light-dependent calcification in Red Sea giant clam Tridacna maxima. Biogeosciences 16:2635-50. doi: 10.5194/bg-16-2635-2019

3. Ravanat, J.-L., Douki, T., and Cadet, J. 2001. Direct and indirect effects of UV radiation on DNA and its components. J. Photochem. Photobiol. B Biol. 63:88-102. doi: 10.1016/S1011-1344(01)00206-8 
4. Holt, A. L., Vahidinia, S., Gagnon, Y. L., Morse, D. E., and Sweeney, A. M. 2014 Photosymbiotic giant clams are transformers of solar flux. J. R. Soc. Interface 11:20140678-20140678. doi: 10.1098/rsif.2014.0678

5. Rossbach, S., Subedi, R. C., Ng, T. K., Ooi, B. S., and Duarte, C. M. 2020. Iridocytes mediate photonic cooperation between giant clams (Tridacninae) and their photosynthetic symbionts. Front. Mar. Sci. 7:465. doi: 10.3389/fmars.2020.00465

SUBMITTED: 21 September 2020; ACCEPTED: 19 July 2021; PUBLISHED ONLINE: 11 August 2021.

EDITED BY: Rúben Martins Costa, King Abdullah University of Science and Technology, Saudi Arabia

CITATION: Rossbach S, Overmans S, Subedi RC and Duarte CM (2021) The Sparkling Tan: How Giant Clams Avoid Sunburns. Front. Young Minds 9:608617. doi: $10.3389 /$ frym.2021.608617

CONFLICT OF INTEREST: The authors declare that the research was conducted in the absence of any commercial or financial relationships that could be construed as a potential conflict of interest.

COPYRIGHT @ 2021 Rossbach, Overmans, Subedi and Duarte. This is an open-access article distributed under the terms of the Creative Commons Attribution License (CC BY). The use, distribution or reproduction in other forums is permitted, provided the original author(s) and the copyright owner(s) are credited and that the original publication in this journal is cited, in accordance with accepted academic practice. No use, distribution or reproduction is permitted which does not comply with these terms.

\section{YOUNG REVIEWER}

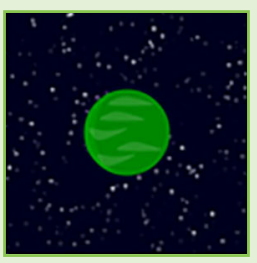

\section{FABIÁN, AGE: 14}

Fabián is a young scientist interested in space exploration and technologies related to a sustainable future. He enjoys developing technical skills in digital design and fabrication which he hopes to implement in the development of future space exploration technologies. Fabián is an avid reader who enjoys biking, diving, programming, acting and world building.

\section{AUTHORS}

\section{SUSANN ROSSBACH}

Susann is a marine researcher who wants to understand how marine animals, such as giant clams and corals, build their skeletons. She is especially interested in learning how they can survive in the changing conditions of our oceans. She loves to dive, explore the underwater world, and share the lessons she learns and pictures she takes underwater with others. *susannrossbach ahotmail.com 

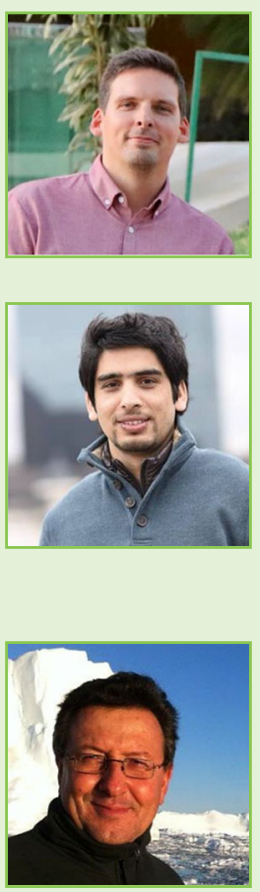

\section{SEBASTIAN OVERMANS}

Sebastian is a biologist who has studied a variety of organisms, ranging from flying bats to sea-dwelling corals. Now he works as a marine scientist in the Red Sea region, where he investigates how UV light interacts with the ocean, and how it affects the health of organisms such as microalgae, corals, and giant clams.

\section{RAM C. SUBEDI}

Ram Chandra is a Ph.D. student in the Photonics Laboratory at King Abdullah University of Science and Technology in the Department of Electrical Engineering. He holds a master's degree in physics from the University of Georgia, USA, as well as a M.Sc. (physics) and B.Sc. (physics and statistics) degrees from Tribhuvan University, Nepal, in 2011 and 2007, respectively.

\section{CARLOS M. DUARTE}

Carlos is a marine researcher who, after nearly four decades documenting how human pressures impact marine life, wants to establish a global effort to rebuild the abundance of marine life. He loves dogs and enjoys being away in the open sea, reading, swimming, snorkeling, walking, and playing with his grandson Oliver. 